\title{
Role of Performance Planning On Strategy Implementation in Commercial State Corporations in Kenya
}

\author{
James Muriuki $^{1}$, Dr Mike Iravo ${ }^{2,}$ Dr Kabare Karanja ${ }^{3}$ \\ ${ }^{l}$ (PhD Candidate, Jomo Kenyatta University of Agriculture and Technology, Kenya) \\ ${ }^{2}$ (Lecturer, Jomo Kenyatta University of Agriculture and Technology, Kenya) \\ ${ }^{3}$ (Lecturer, Jomo Kenyatta University of Agriculture and Technology, Kenya)
}

\begin{abstract}
The purpose of this study was to look at the role of performance contracting in strategy implementation in commercial state corporations in Kenya. Strategy development and execution is key in enhancing organizational competitiveness. Among the strategy implementation tools, performance contracting plays a key role in engaging organizational staff. Problems in performance contracting and strategy implementation in state corporations led the researcher to formulating a research problem which guided the research process. The results will be used to solve strategy implementation problems thus improving performance. The general objective of this study was to analyse the role of performance contracting in strategy implementation in commercial state corporations in Kenya. The study used descriptive research design. The strategy implementation (dependent) variable was measured by Resource allocation and deployment; and the Performance Contracting (Independent) variables include Performance Target Setting, Performance Planning, and Performance Monitoring and Reporting. The study was based on the Resource Based theory and the Goal Setting theory. The target population for this study was the 32 Commercial State Corporations in Kenya as listed in the State Corporations Advisory Committee (SCAC) website (2016). Primary data was collected using structured questionnaires. The data was analyzed using descriptive statistics; correlation and regression analysis was computed to determine the degree of association between performance contracting and strategy implementation. The study established that Performance planning have a significant influence on strategy implementation. The study contribute significantly to new knowledge, in policy formulation, effective implementation of the Kenya Vision 2030, effective implementation of strategy using performance contracting, enhanced service delivery by the state corporations, and general performance of State Corporations in fulfillment of their mandates.
\end{abstract}

Keywords: Performance contracting, strategy implementation, performance planning

\section{Background of the Study}

\section{Introduction}

'Most leaders fail-not in the formation of strategy but in its implementation' (Edinger, 2012). According to Edinger, (2012) if strategy is to be implemented well, it should be cascaded throughout the organization and get to the practical and tactical components of people's jobs every day. Managers should be involved in this process, and should translate the elements of the strategy for the organization to their own functional areas. Doing this allows them to develop and own the process of cascading the strategy and designing implementation plans with high likelihood of execution. Government of Kenya has been using the performance contract to assist the public sector in implementing the national as well as the organizational strategies.

The reason why strategy implementation fails is that managers do not have practical models to guide their actions during implementation. Without adequate models, they try to implement strategies without a good understanding of the multiple factors that must be addressed, often simultaneously to make strategy work (Okumus, 2003). This is supported by Rumelt (2011) who noted that less $10 \%$ of well formulated strategies are effectively executed and concluded that it is better to have a less excellent strategy which is fully implemented than to formulate an excellent strategy which is never or only partially executed. Cobbold (2010) in a study in the times $1000,80 \%$ of directors interviewed said they had the right strategy but only $14 \%$ of them thought the strategies were well implemented.

Strategy implementation is the amplification and understanding of a new strategy within an organization (Mintzberg, 1994). Such an explanation involves the development of new structures, processes and other organizational alignments (Galbraith \&Kazanjian, 1986). Implementation is a key stage of the strategy process, but one which has been relatively neglected (Noble, 1999, Dobni and Luffman 2003, Bantel and Osborn, 2001). Despite this it is generally perceived as a highly significant determinant of performance (Mbaka \& Mugambi, 2014). As Noble (1999) states, "well formulated strategies only produce superior performance for the firm when they are successfully implemented". 
There seems to be widespread agreement in the literature regarding the nature of strategic planning, which includes strategy implementation (Mbaka \& Mugambi, 2014). It includes presentations of various models showing the organizational characteristics suggested as significant factors for effective strategy implementation (Guffy, 1992). It is also portrayed as a lively process by which companies identify future opportunities (Reid, 1989). Additionally, the existence of a strategy is an essential condition or precondition for strategy implementation. Implementation is focused by nature and by definition. It cannot be directionless. It is a process defined by its purpose - in this case, the realization of a strategy. Thus, to implement a strategy, there must be a strategy (Mbaka \& Mugambi, 2014). The strategy may be more or less well-formed, more or less in the process of formation, or even emergent (Mintzberg, 1987). Unless it is suitably formed to represent a direction or goal, there is nothing to implement; and organizational members will be unable to work towards its realization. As a result, strategic intentions are inextricably linked with, and enable the existence of, strategy implementation. As well, organizations that focus their energy on harvesting the fluid relationship between strategy and implementation will create satisfied customers, employees, and greater profits (Beaudan, 2001).

\section{Global and Africa perspective}

Performance contracting started in the 1970's in France. Since then it has been used by various countries all over the world particularly by developing countries. In Asia it has been used in Bangladesh, China, India, Korea, Pakistan, and Sri Lanka. In Africa it has been used in Benin, Burundi, Cameroon, Cape Verde, Cote d'voire, Gabon, Ghana, Guinea, Madagascar, Mali, Mauritania, Morocco, Niger, Senegal, Togo, Tunisia, and D.R.Congo. In Latin America it has been used by Argentina, Brazil, Bolivia, Chile, Colombia, Mexico, Uruguay and Venezuela. It has also been used in Malaysia, United Kingdom, United States of America, Canada, Denmark, and Finland.

Performance contracts were implemented to improve performance to deliver quality and timely services to the citizens; improve productivity in order to maximize shareholders wealth; reduce or eliminate reliance on the exchequer; instill a sense of accountability and transparency in service delivery and the utilization of resources; give autonomy to government agencies without being subjected to the bureaucracies and unnecessary procedures. The results of performance contracting from the countries have been mixed with some experiencing improvements and others none due to unclear and conflicting objectives, and lack of autonomy and accountability (Kobia \& Mohammed, 2006). According to Kobia \& Mohammed (2006) for public enterprises to gain from performance contracting they should involve the citizens and allow them to manage the processes rather than use expatriates, they should also allocate adequate resources to the organization, select few realistic targets rather than too many objectives at once, and the governments should provide financial resources to the enterprises.

\section{Kenya perspective}

Kenya attained independence in 1963. Since then, the Government has been struggling with development challenges through numerous development plans, sessional papers, fiscal papers and recovery papers. These include Sessional Paper No. 10 of 1965 on "African Socialism and its Application in Planning and Management", Sessional Paper No. 1 of 1986 on "Economic Management for Renewed Growth", Sessional Paper no. 1 of 1994 on "Recovery and Sustainable Development to the year 2010", the Poverty Reduction Strategy Paper (PRSP) of 2002, and the Economic Recovery Strategy for Wealth and Employment Creation (ERS) of 2003, among many other national and sectoral strategy documents (Ikiara, et al., 2008).

The Government of Kenya adopted Performance Contracting (PC) in public service as a strategy for improving service delivery to Kenyans (Kobia \& Mohamed, 2006), to enhance efficiency and effectiveness together with probity and integrity, and in effort to achieve the objectives and targets of Economic Recovery Strategy for Wealth and Employment Creation (ERS) 2003-2007 and to manage performance challenges in public service. According to Kobia \& Mohamed (2006) performance contracts were introduced to; Improve performance to deliver quality and timely services to the citizen, Improve productivity in order to maximize shareholders wealth, Reduce or Eliminate reliance on the exchequer, Instill a sense of accountability and transparency in service delivery and the utilization of resources, and to give autonomy to government agencies without being subjected to the bureaucracies and unnecessary procedures. Although the performance contract is supposed to be developed by individual organizations borrowing from their strategic plans, it has its own set of objectives on which organizational objectives are added. One of which is development of a strategic plan. Most of the state corporations and other government ministries and departments have been experiencing problems in aligning the objectives of the Kenya Vision 2030, the performance contract, and their strategic plans. Some have other performance management tools on top of the performance contract; this totally complicates management of the organizations and ensuring they focus on their core mandate. This is a unique situation experienced by organizations under government performance contracting in Kenya which has not been experienced and has not been researched before anywhere else in the world. 
On May 6, 2010, the then Right Hon. Prime Minister of the Republic of Kenya appointed a Panel of experts to review the Performance Contracting and Evaluation in the public sector so as to make recommendations to the Government on how to improve the system. The panel noted that there is a disparity between performance management contracting and other performance management tools and instruments. They also noted that there is neither an adequate link between performance contracting and budgeting system nor a clear link of national priorities with the performance contracting. The panel also noted the need to improve the current performance contracting matrix as it does not clearly capture performance of the public service institutions. It was noted that there are too many matrices thus raising concern over the use of results for ranking and ignoring the fact that all the institutions have mandates to deliver and customers to serve as spelt out in the various Acts of Parliament. The panel also noted a difference between the results from the primary evaluation and the results finally announced, this is due to moderation of results (Panel of experts on review of performance contracting, 2010).

According to the report on evaluation of the performance of public agencies for the financial year 2010/2011 (2012); a total of 468 Government agencies signed performance contracts between July and December, 2012. Which are; 46 Ministries and Accounting Departments, 178 State Corporations, 175 Local Authorities and 69 Tertiary Institutions in the Ministries of Education and Higher Education, Science and Technology. Two state corporations and two Local authorities did not submit their performance for evaluation. Six State Corporations did not sign performance contracts during the year under review.

The commercial state corporations are state enterprises expected to generate revenue or make profit. State enterprises were established include the expectation that they were to earn a surplus to accomplish other societal goals, produce goods and services deemed necessary for development, engage in projects which require large capital outlay, are necessary for development but are unattractive to the private sector and to provide direction, regulation and support to the commercial enterprises and act as a consumers watchdog. The government of Kenya has encouraged the co-existence of private and pubic enterprises to enable it achieve its key objectives as enshrined in the constitution at independence of eradicating poverty, ignorance and disease (Nderi, 2013).

Karanja (2004) emphasizes that whereas the private enterprise has entrepreneurial roots, public corporations are created by some higher controlling authority with multiple and competing interests. The purpose and objectives of the state enterprise is defined by that higher controlling authority who also provide the operating resources on which it depends. In the past most of these commercial state corporations have been heavily relying on state funding instead of generating the expected revenues. Most of the commercial state corporations made losses, lacked accountability and transparency in service delivery and the utilization of resources (Nderi, 2013).

Decision making in the public sector is a political process Karanja (2004). This makes attainment of simple objectives a time consuming and tedious process not worthy devoting some level of resources. Challenges of strategy implementation abound due to the fact that managing the implementation and execution process is an operations oriented activity which aims at making things happens to support core business activities in a strategy supportive manner. It is easily the most demanding and time consuming part of the strategy management process. The process of converting strategic plans into actions and results tests a manager's ability to direct organizational change, motivate people, build and strengthen company competencies and competitive capabilities. It also tests the ability to create and nurture a strategy supportive work climate in executing the strategy proficiently together with initiatives, which are launched and managed from many organizational fronts. As a result of all these initiatives, many institutional and operational challenges are bound to be faced by any organization whether in commercial or public sector (Strickland \& Gamble, 2008).

\section{Statement of the problem}

It has been observed that the organizations focus heavily on the performance contract thereby neglecting many aspects of the strategic plan implementation. In most cases they focus on the performance contract since they are required to periodically report to the performance contracting department in the Ministry of Devolution and Planning on the progress of the performance contract (GoK, 2010). They therefore disregard implementation of many aspects of their strategic plan which is retrieved from the shelves at time of periodical reviews. This makes employees lose focus and hence affect the organizations performance and overall implementation of strategy. It brings about conflicting and misaligned goals and objectives demands on employees. In some cases the performance targets of similar goals and objectives of performance contract and strategic plan do not tally. Roney (2004) observed that the most common reason for firms' failure is linked to wrong strategy implementation. During quarterly and annual performance reviews it has been observed that there is a loss of focus amongst employees as they do not know which objectives to work with and they are required to deliver on both. It was also observed by the performance contracting department in the 2010/2011 performance contracting report that there is a visible mismatch between annual work planning of public 
agencies and performance contracting, and that similar discrepancies are visible between annual organization reports and annual performance contract reports. According to Panel of experts on review of performance contracting, 2010, Performance contracting has raised dissatisfaction on the results as they do not relate to improved performance in terms of service delivery from the public. Ministries, departments and Agencies have also on various occasions challenged the results of performance contracting. The dissatisfaction and public outcry led to failure of release of the 2007 performance contracting results (GoK, 2012). The panel of experts on review of performance contracting (2010) noted that there is no adequate linkage between performance contracting and the budgeting system, and no clear line of sight from performance contracting to the national priorities. The panel also noted the existence of too many matrices and ignoring the mandate of the respective institutions as stipulated in various Acts of parliaments and legal notices, and their mandated service to customers. Therefore, there is a need to establish the role of performance contracting in strategy implementation in commercial state corporations in Kenya.

\section{General objective of the study}

To analyze the role of performance contracting in strategy implementation in commercial state corporations in Kenya

\section{Specific objective of the study}

i. To evaluate role of performance planning on strategy implementation in commercial state corporations in Kenya.

\section{Research Hypotheses}

$\mathrm{H}_{0}$ Performance planning has no significant influence on strategy implementation in commercial state corporations in Kenya.

\section{Conceptual Framework}

Several types of conceptual frameworks for the field of public administration were identified by Shields and Tajalli (2006). The frameworks are linked to particular research purposes. As discussed by Kobia and Mohamed (2006) in the Result Based Management model, the performance contracting independent variables to be adopted in this study are; Performance Target Setting, Performance planning, and Performance Monitoring and Reporting. The Strategy implementation dependent variable to be adopted in this study is resources allocation. The resource allocation variable have been identified to measure the extent to which a strategy is being implemented by various researchers such as Gitonga (2013), Valentina (2013), Kalali, et.al (2011), Hrebiniak (2006), Allio (2005), Ibrahim et al, (2012) and Beer \& Eisenstat (2000).

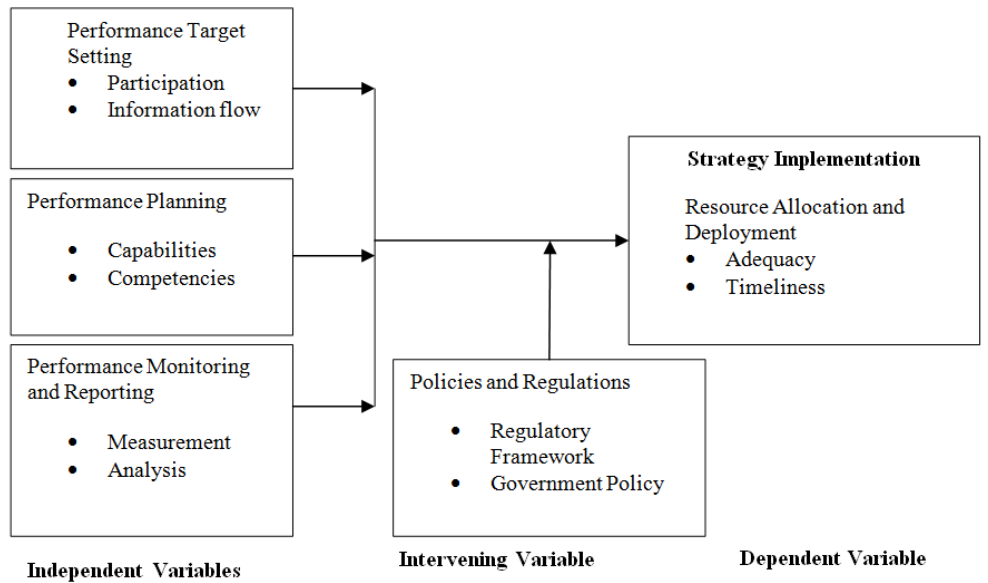

Figure 1: 1 Conceptual Framework

\section{Performance Planning}

\section{Review of literature}

Senior leaders should play a role in ensuring performance planning aligns corporate strategy and objectives to individuals, so that employees know how what they do fits with the organisation's overall strategy (Chubb, Reilly, and Brown, 2011). This is known as the 'golden thread' of performance management (IDeA, 2004). Stiffler (2006, cited in Wikina, 2008) recommends that a 'unified approach to performance management' is achieved through aligning the objectives, resources and activities of the organisation to the goals and opportunities of individuals within the organisation (Karuhanga, 2010). 
Lawson et al. (2003, cited in Elzinga et al., 2009) found through research in 150 organisations, that two-thirds agreed that implementing performance management systems increased employees' awareness of company strategy and business plan goals, and helped to align operational improvements with overall strategy. Wikina (2008) found that the need to align performance and goals with organisational strategy is causing organisations to examine the performance management structures they have in place and devise ways to make them more effective and outcome-based.

According to Cascio (1991, cited in Sillup et al, 2010) performance planning should 'help managers groom their employees to accomplish objectives that will help the corporation gain competitive advantage and Borman (1991, cited in Sillup, 2010) equally argues that effective performance planning requires relevance; through which there are clear links between the tasks for a job and organisational objectives. Murphy (2004) criticises that organisational goals for performance appraisal systems are not considered carefully enough and this results in systems attempting to achieve too much. Moreover, Murphy and Cleveland (1995) make the point that the organisational goals for the appraisal system need to be compatible with what the appraiser and appraisee want to get out of it. If not, they will not use it effectively. The implication here is that many of the organisational purposes of appraisal are not of great value to the manager or the employee, so their compliance will at best be half-hearted and they may well consciously distort the process to achieve their own desired ends.

In a series of studies, Locke and Latham (1990) have shown strong evidence for the effectiveness of individual goal setting, although the majority of such work has not been done in the context of performance planning. They advocate the use of goals that are specific, moderately difficult, and accepted by the individual for whom they are set. The recurring theme here is about goals which the employee really agrees with, not goals which are imposed.

Alongside the importance of aligning employee's efforts with company objectives is the need to clearly communicate the organisation's expectation of its employees (Chubb, et al, 2011. The Corporate Leadership Council (2002) concluded that employee understanding of performance standards and objectives is more influential than specific features of the performance management system itself in driving performance. The Acas Model Workplace also indicates that employees require clarity around expectations of them in terms of standards of performance and behaviour and they need consistency in the application of processes. Acas state that at an individual performance planning is the 'ideal way of clarifying objectives' and that appraisals provide the opportunity for managers to check that employees understand what is expected of them (Acas, 2005). Wikina (2008) also states that in performance planning, expectations for employees need to be stated with clear, measurable performance goals.

\section{Research design}

\section{Research Methodology}

According to Sekaran \& Roger (2011), research design is a master plan that specifies the methods and procedures for collecting and analyzing the needed information. Cooper and Schindler (2011) argue that research design constitutes the collection, measurement, and analysis of the data to achieve for stated objectives. The study adopted a descriptive research design, which can also be referred to as a survey design (Kothari, 2004). According to Kothari (2004) descriptive studies are those studies concerned with describing the characteristics of a particular individual or group; they are concerned with specific predictions, narration of facts and characteristics concerning individuals or groups.

\section{Target Population}

According to Cooper \& Schindler (2011) population is the total collection of elements that form the main focus of a scientific query. According to Mugenda \& Mugenda (2003) population is a complete set of individuals or cases with some common observable characteristics and that differentiate it from other populations, and a target population is that population to which a researcher wants to generalize the results of a study. The thirty two (32) Commercial state parastatals in Kenya as at the year 2016 formed the population under study. Among the state corporations in Kenya, commercial state corporations face major competition in the market as they largely operate in the business competitive environment. Efficient and effective implementation of strategy is of greater importance to them than the other state corporations tasked with the state mandate of service delivery to citizens.

\section{Sampling Frame}

According to Cooper \& Schindler (2011) and Mugenda \& Mugenda (2003) sampling frame is the list of elements from which the sample is drawn. According to Kothari (2004) it contains the names of all items of a population, and it should be comprehensive, correct, reliable and appropriate. The study population was the Commercial State Corporations in Kenya. There were thirty two (32) Commercial /Manufacturing State Corporations in Kenya listed in the State Corporations Advisory Committee (SCAC) website, www.scac.go.ke. 
Table 3. 1: Sampling Frame

\begin{tabular}{|l|c|c|c|}
\hline Population & Sample Size & No of respondents per sample & Total number of respondents \\
\hline 32 Commercial State Corporations & 25 & 10 & 250 \\
\hline
\end{tabular}

\section{Sampling technique and sample size}

Sample size refers to the number of items to be selected from the population to constitute a sample (Kothari, 2004). According to Mugenda \& Mugenda (2003) a sample is a subset of a particular population. A good and valid sample should be a representative of the target population (Kitchenham \& Pfleeger, 2002). The sample size was calculated using Nasiuma (2000) formula which is illustrated as follows:

$$
\mathrm{n}=\overline{\mathrm{C}}+\frac{\mathrm{NC}}{\mathrm{N}-1)} \mathrm{e}^{2}
$$

Where: $n, N, C$, e represent the sample size, the population, the coefficient of variation (0.5), and the precision level (0.05) respectively. The formula is used to calculate the sample as shown

$$
\begin{aligned}
& \mathrm{n}=-32 \times 0.5^{2} \\
& 0.5^{2}+(32-1) 0.05^{2} \\
& \mathrm{n}=24.8 \\
& \mathrm{n}=25 \text { state corporations }
\end{aligned}
$$

The target population under the study was 32 commercial state corporations and using the above formula, the estimated sample size was 25 commercial state corporations. The 25 state corporations constituting the sample were selected using simple random sampling method. In this case, all commercial state corporations had an equal chance (probability) of being selected to participate in the study. Ten (10) respondents from each commercial state corporation were purposively selected. The respondents were heads of departments or head of sections as they are engaged in performance contracting and strategy development and implementation.

\section{Data Collection Instruments}

Primary data was collected; primary data are those which are collected afresh and for the first time (Kothari, 2004). According to Kothari, (2004), there are methods for collecting primary data in descriptive research, which include; observation, interviews, questionnaire, schedules, warranty cards, etc. In this study the primary data was collected using a questionnaire with structured and unstructured questions. According Mugenda \& Mugenda (2003) structured questions refers to questions which are accompanied by a list of possible alternatives from which respondents select the answer that best describes their situation, and unstructured questions are questions which give the respondent complete freedom of response. The questionnaires were hand delivered to the selected respondents. The method is most extensively employed in various economic and business surveys (Kothari, 2004).

\section{Data collection procedure}

The survey questionnaires were delivered to and collected from the respondents. Respondents were required to respond to the questions and return the questionnaire to the researcher. Respondents were Managers in charge of corporate planning or equal in the state corporations.

\section{Pilot Study}

As recommended by Kothari (2004), a pilot study was carried out to assess the feasibility, appropriateness, and practicability of the research design, by administering the survey questionnaire to $1-10 \%$ of sample size as proposed by Mugenda \& Mugenda (2003) of state corporations. Therefore, three non commercial state corporations were selected for the pilot study. The questionnaire was tested for validity and reliability after pre-testing and corrections made. Validity indicates the degree to which an instrument measures what is supposed to measure and the instrument is reliable if it provides consistent results (Kothari, 2004).

The analysis of reliability was done to value the level of reliability of the data gained from the research. It aims to help the researchers to assume whether the data collected are reliable or not reliable. Cronbach $a$ 's was computed as a measure for construct reliability, it was 0.912 , which indicated a strong level of reliability. According to Nunally (1978), the nearer the value of reliability to 1.00, the more reliable the result would be. The value of reliability which is less than 0.7 is assumed to be weak while for the value of reliability which is in the range of 0.70 is the accepted. Moreover, the value which is more than 0.80 is assumed to be strong.

\section{Data analysis and presentation}

The collected data was processed and analyzed. Processing included editing, coding, classification, and tabulation to make the data amenable to analysis (Kothari, 2004; \& Mugenda \& Mugenda, 2003). The SPSS software version 20.0 was used for data processing and analysis. Analysis refers to the computation of certain 
measures along with searching for patterns of relationships that exist among data groups (Kothari, 2004). The data was presented in charts and tables. Principal component analysis was done for each variable to obtain component scores, which were then used in regression analysis. Multiple regression was used to study functional relationship existing between two or more variables to determine how one or more variables affect other variables (Kothari, 2004). SPSS software version 20.0 provided flexibility in the data processing and analysis.

\section{Data Analysis}

99.3\% of the valid respondents agree that performance planning influence strategy implementation. $90.6 \%$ of the valid respondents agreed, $6.6 \%$ strongly agreed, and $0.6 \%$ strongly disagreed that performance contracting ensures employees are trained on performance planning so as to implement strategic plan. $83.9 \%$ of the valid respondents agreed, $8.9 \%$ strongly agreed, and $0.6 \%$ disagreed that performance contracting enhances capability of employees to plan for implementation of performance contract and strategic plan. $79.6 \%$ of the valid respondents agreed and $8.3 \%$ strongly agreed that Performance contracting enhances development of a standardized work plan format in the organization for implementation of performance contract that aids in strategy implementation. $61.1 \%$ of the valid respondents agreed, $10.6 \%$ strongly agreed, and $2.8 \%$ disagreed that performance contracting enhance adequate staffing of the organization for implementation of the strategic plan. $74.3 \%$ of the valid respondents agreed, $7.3 \%$ strongly agreed, and $1.1 \%$ disagreed that performance contracting assist the organization in hiring of competent staff for implementing the organization's strategy. $78.7 \%$ of the valid respondents agreed, $4.5 \%$ strongly agreed, and $1.7 \%$ disagreed that performance contracting ensures staff involved in performance planning and strategy implementation are competent. $78.7 \%$ of the valid respondents agreed, 5.1\% strongly agreed, and $0.6 \%$ disagreed that performance contracting ensures staff competence is considered in allocation of work and strategy implementation. $78.3 \%$ of the valid respondents agreed, $5.0 \%$ strongly agreed, and $1.1 \%$ disagreed that performance contracting ensures employees goals are regularly updated to align with business objectives. $78.3 \%$ of the valid respondents agreed, $6.1 \%$ strongly agreed, and $2.2 \%$ disagreed that performance contracting ensures adequate resources are allocated during performance planning for strategy implementation. $82.1 \%$ of the valid respondents agreed, 5.6\% strongly agreed, and $1.7 \%$ disagreed that performance contracting ensures managers are skilled in performance coaching, and give timely, actionable feedback for performance plans and strategy implementation.

Principal component analysis was carried out to get factor scores for regression analysis as the data was categorical. The KMO statistic varies between 0 and 1 . A value of 0 indicates that the sum of partial correlations is large relative to the sum of correlations, indicating diffusion in the pattern of correlations (hence, factor analysis is likely to be inappropriate). A value close to 1 indicates that patterns of correlations are relatively compact and so factor analysis should yield distinct and reliable factors (Field, 2009). Kaiser (1974) recommends accepting values greater than 0.5 as barely acceptable. According to Hutcheson \& Sofroniou (1999) values between 0.5 and 0.7 are mediocre, values between 0.7 and 0.8 are good, values between 0.8 and 0.9 are great and values above 0.9 are superb. KMO test result for this variable was 0.651 which was above 0.5 indicating the adequacy of the sample size.

On carrying out the principal component analysis, one factor was extracted with loadings over 0.5 composed of 5 variables. Composite scores for the factors was then carried out using the data reduction procedure in SPSS and a single regression factor computed for the one factor. Linear regression on factor component scores was carried as the data was categorical. The factor was then regressed on the dependent variable generating the following output.

The role of performance planning on strategy implementation was determined by carrying out a regression analysis between the dependent variable strategy implementation, and the independent variable, role of performance planning on strategy implementation. On running a correlation matrix, there was no multicollinearity in the data as there are no substantial correlations $(r>.9)$ between predictors. on running the regression analysis, the proportion of the variance explained by the model was $0.190(\mathrm{R}=0.190)$. The improvement of the model on adding independent variable was good as $\mathrm{R}^{2}$ changes to 0.036 ; the change was significant as the Sig. F change (0.036) was less than 0.05 at $95 \%$ confidence level. The regression model was a significant fit of the data overall, as the sig $=0.030$ in the ANOVA table at $95 \%$ confidence level. Finally, the assumption that errors in regression are independent was met; this as the Durbin-Watson statistic (2.166) was close to 2 (and between 1 and 3), as recommended by Field (2009). The coefficients (B value $=0.176$ ) indicated the contribution of the predictor to the model. The contribution was significant as the sig value $(0.030)$ at $\alpha=0.05$ was less than the recommended maximum sig. value of 0.05 . Therefore, the null hypothesis $\mathrm{H}_{0}$ : Performance planning has no significant influence on strategy implementation in commercial state corporations in Kenya was rejected. 


\section{Summary, Conclusion, And Recommendations}

Adequacy of sample size was determined using the KMO measure of sampling adequacy and validity was tested using the Bartlett's test of sphericity. The KMO statistic varies between 0 and 1 . A value of 0 indicates that the sum of partial correlations is large relative to the sum of correlations, indicating diffusion in the pattern of correlations indicates that patterns of correlations are relatively compact and so factor analysis should yield distinct and reliable factors values greater than 0.5 as barely acceptable. According to Hutcheson \& Sofroniou, (1999), values between 0.5 and 0.7 are mediocre, values between 0.7 and 0.8 are good, values between 0.8 and 0.9 are great and values above 0.9 are superb. All the KMO test results for the four variables were above 0.5 indicating the adequacy of the sample size. According to Field (2009), Bartlett's Test of Sphericity Taking a $95 \%$ level of Significance, $a=0.05$ the p-value valid. For all the four variables, the sig of 0.000 was less than 0.05 at $95 \%$ confidence level, therefore indicating the data as reliable. The response rate was good as out of the 250 targeted respondents, 181 responded which accounts for $72.4 \%$ response rate. $99.3 \%$ of the valid respondents agreed that performance planning influence strategy implementation. Principal component analysis was carried out to get factor scores for regression analysis as the data was categorical. On carrying out the principal component analysis, one factor was extracted with loadings over 0.5 composed of 5 variables. Composite scores for the factors was then carried out using the data reduction procedure in SPSS and a single regression factor computed for the one factor. Linear regression on factor component scores was carried as the data was categorical. The factor was then regressed on the dependent variable.

The role of performance planning on strategy implementation was determined by carrying out a regression analysis between the dependent variable strategy implementation, and the independent variable, role of performance planning on strategy implementation. On running a correlation matrix, there was no multicollinearity in the data as there are no substantial correlations $(r>0.9)$ between predictors. The proportion of the variance explained by the model was $0.190(\mathrm{R}=0.190)$. The improvement of the model on adding independent variable was good as $\mathrm{R}^{2}$ changed to 0.036 ; the change was significant as the Sig. F change $(0.036)$ was less than 0.05 at $95 \%$ confidence level. The model was a significant fit of the data overall, as the sig was 0.030 at $95 \%$ confidence level. Finally, the assumption that errors in regression are independent was met; this as the Durbin-Watson statistic (2.166) is close to 2 (and between 1 and 3), as recommended by Field (2009). The contribution of the independent variable was significant as $b$ value $(0.176)$ was significant as indicated by the sig value $(0.030)$ at $\alpha=0.05$ was less than the recommended maximum sig. value of 0.05 . Therefore the null hypothesis $\mathrm{H}_{0}$ : Performance planning has no significant influence on strategy implementation in commercial state corporations in Kenya was rejected.

It was concluded that the influence of performance planning on strategy implementation was statistically significant, at $95 \%$ confidence interval. Performance planning activities are supportive of strategy implementation. Therefore, state corporations should enhance the performance planning activities and link them to strategy as the factor for increasing the odds of enhancing strategy implementation was low.

\section{Acknowledgements}

Special thanks go to Jomo Kenyatta University of Agriculture and Technology management and my supervisors, Dr. Mike Iravo and Dr. Kabare Karanja for their assistance and guidance. I also thank my family for their support; my wife and my sons; and my parents and my siblings. And much thanks to the Almighty God.

\section{References}

[1]. Edinger, S. (2012). The Three Cs of Implementing Strategy. Forbes, 7th Aug, 2012.

[2]. Okumus, F. (2003). A framework to implement strategies in organizations. Emerald Journal Management Decisions, pp. 871-882

[3]. Richard, P., Rumelt. (2011).Good Strategy/Bad Strategy. Crown Business, New York

[4]. Cobbold, L., \& Lawrie, G. (2010). How to create sustainable competitive advantage using strategy mechanism. Retrieved from http://www.slideshare.net/Petrilau

[5]. Mintzberg, H. (1994). Rethinking strategic planning part II: New roles for planners. Long Range Planning, Vol. 27, No. 3, pp. 2230

[6]. Galbraith, J. R., \& Kazanjian, R. K. (1986), Strategy Implementation, Structure Systems and process, St. 12 Paul, MN: West Publishing.

[7]. Noble, C.H. (1999).The Eclectic Roots of Strategy Implementation Research. Journal of Business Research, 45,119 - 134

[8]. Dobni, C.B., and Luffman, G., (2003). Determining the Scope and Impact of Market Orientation Profiles on Strategy Implementation and Performance. Strategic Management Journal, 24: 577- 585.

[9]. Bantel, K. A., \& Osborn, R. N. (2001). The influence of performance, environment and size on the identifiability of firm strategy. British Journal of Management, 6(4), 235-248.

[10]. Mbaka, R.M., \& Mugambi, F. (2014). Factors affecting successful strategy implementation in the Water Sector in Kenya. IOSR Journal of Business and Management (IOSR-JBM), Vol 16, issue 7, pp 61-68

[11]. Guffy, W.R. (1992).The role of organization communication in the implementation of a business unit strategy. Doctoral dissertation, Virginia Polytechnic Institute and State University. VA.

[12]. Mintzberg, H. (1987). The strategy concept I: Five Ps for strategy. California Management Review.

[13]. Beaudan, E. (2001). The failure of strategy. It's all in the execution. Ivery business, Journal, 65 (3), 64 - 68

[14]. Kobia, M., \& Mohammed, N. (2006). The Kenya experience with performance contracting. KIA, Nairobi.

[15]. GoK. (2010). Panel of Experts on Review of Performance Contracting and Evaluation. 
[16]. GoK. (2012). Report on Evaluation of the Performance of Public Agencies for the Financial year 2011/2012.

[17]. Nderi, H.W. (2013). Performance contracting and strategy implementation in Commercial state corporations in Kenya. Unpublished MBA thesis, UoN.

[18]. Hough, J, Thomson, AA, Strickland, AJ \& Gamble, JE. (2008). Crafting and Executing Strategy. South African ed., London. McGraw-Hill.

[19]. Roney, C.W. (2004). Strategic Management Methodology. New York, Praeger Publishers.

[20]. Shields, P., \& Tajalli, H. (2006). Intermediate theory: The missing link to successful scholarship. Journal of Public Affairs Education, 12, 313-334

[21]. Kalali, N.S. (2011). Why does strategic plans implementation fail? A study in the health service sector of Iran. Africa Journal of Business Management. 9831-9837

[22]. Hrebiniak, L. (2006). Obstacles to effective strategy implementation: organizational dynamics. International Journal of Management Studies. Vol. 35, pp. 12-31.

[23]. Allio, M.K. (2005). A Short, Practical Guide to Implementing Strategy. Journal of Business Strategy, 26, 12-21

[24]. Ibrahim, M., Sulaiman, M., Kahtani, A.A., \& Abu-Jarad, I. (2012). The relationship between strategy implementation and performance of manufacturing firms in Indonesia: The role of formality of structure as a moderator. World Appliances Sciences Journal, Vol. 20, Issue 7, pp. 955-964.

[25]. Beer, M., \& Eisenstat, R.A. (2000). The silent killers of strategy implementation and learning. Sloan Management Review, 41 (4): $29-41$

[26]. IDeA (2004), Performance management: the people dimension, Ref: IDEA035 ISBN: 0748892273

[27]. Wikina, S.,B. (2008). Effective performance improvement and management strategies for the information technology industry. International Society for Performance Improvement. Vol. 47, issue 9, pp. 2-48

[28]. Karuhanga, B. N. (2010). Challenges of performance management in universities in Uganda, International Research Symposium in Service Management, Le Meridien Hotel, Mauritius, 24-27 August 2010

[29]. Elzinga, T., Albronda, B., \& Kluijtmans, F. (2009). 'Behavioural factors influencing performance management systems' use', International Journal of Productivity and Performance Management, Vol. 58, No. 6

[30]. Sillup, G. P., \& Klimberg, R. (2010). Assessing the ethics of implementing performance appraisal systems. Journal of Management Development, Vol. 29, No. 1

[31]. Murphy, T. H. (2004). Performance Appraisals, ABA Labor and Employment Law Section Equal Employment Opportunity Committee, Mid-winter meeting, March 24-27

[32]. Murphy, K. R., \& Cleveland, J. N. (1995) Understanding Performance Appraisal, Thousand Oaks: Sage

[33]. Locke, E., \& Latham, G. (1990). Work Motivation: The High Performance Cycle, in Kleinbeck U, et al. (eds.), Work Motivation, Hillsdale NJ: Lawrence Erlbaum

[34]. Chubb, C., Reilly, P., \& Brown, D. (2011). Performance management literature review. IES HR Network, Brighton, UK.

[35]. Corporate Leadership Council (2002). Performance Management Survey

[36]. Acas (2005). The Acas Model Workplace, Acas, July 2005

[37]. Sekaran, U., \& Roger, B. (2011). Research Methods for Business, A skill Building Approach. 4th Ed, New York, Inc \&Sons.

[38]. Cooper, D.R. \& Schindler, P.S. (2011). Business Research Methods. 11th Ed. New Delhi, McGraw-Hill, Inc.

[39]. Kothari, C.R. (2004). Research Methodology: Methods and Techniques. 2nd Ed. New Delhi, Washua Prakasha Publishers.

[40]. Mugenda, O.M., \& Mugenda, A.G. ((2003). Research Methods: Quantitative and Qualitative Approaches. Nairobi, Kenya, ACTS Press.

[41]. Kitchenham, B., \& Pfleeger, L. (2002). Principles of survey research. Software

[42]. Nassiuma, K. (2000). Survey sampling: Theory and methods. Nairobi, Kenya: Nairobi

[43]. Nunnally, J. C. (1978). Psychometric theory (2 ${ }^{\text {nd }}$ ed.). New York: McGraw-Hill.

[44]. Field, A. (2009) Discovering Statisitics using SPSS, 3rd ed, Sage, London

[45]. Kaiser, H. F. (1974). An index of factorial simplicity. Psychometrika, 39, 31-36.

[46]. Hutcheson, G., \& Sofroniou, N. (1999). The multivariate social scientist. London: Sage. 